\title{
The Old One-Two: \\ Preserving Analytical Dualism in Psychological Sociology*
}

\author{
Stephen Vaisey \\ Duke University \\ Margaret Frye \\ Princeton University
}

January 28, 2016

* We would like to thank Gabe Ignatow and Omar Lizardo for a stimulating discussion that improved this paper. Address correspondence to: stephen.vaisey@duke.edu 


\section{The Old One-Two: Preserving Analytical Dualism in Psychological Sociology}

Among contemporary microsociologists, three related beliefs are increasingly common. The first is that sociology suffers from the lack of a coherent "theory of action." On this view, sociologists differ from, for example, economists (who have expected utility maximization) or personality psychologists (who have traits) because we rely on a troublingly ad hoc mix of norms, sanctions, social influence, power seeking, and crypto-rational instrumentalism to explain human conduct (see Campbell 1996; Smith 2003). The second belief is that sociologists should pay more attention to research in the cognitive sciences (used here broadly to include psychology, neuroscience, and related disciplines) to outline a set of cognitively realistic principles that can inform the construction of a better theory of action (see e.g., DiMaggio 1997; Lizardo 2007; Vaisey 2009). The third belief is that the theoretical tradition of Pierre Bourdieu can serve as a bridge between sociology and the cognitive sciences that will facilitate better answers to questions about why people do the things they do (Lizardo 2004; Ignatow 2009; Vaisey 2009).

We share these three beliefs, though we hasten to add that the dialogue between cognitive science and microsociology has barely begun. Even among the subset of cognitive sociologists who agree that the "Bourdieusian bridge" is especially promising, fundamental issues remain underexplored. A particular danger at this stage is that superficial similarities between positions can mask disagreements (or potential disagreements) on issues that are important for conducting and interpreting empirical research.

In our view, the most important issue surrounding the Bourdieu-cognitive science fusion-and the one we will explore in the paper-is how to conceive of the various binary oppositions subsumed under the rubric of "dual-processing" models of cognition (Vaisey 2009). Though not all research in this domain can be subsumed under a unitary "system 1 - system 2" framework, most psychologists and neuroscientists recognize a wide variety of contrasts that map roughly onto an analytical distinction between "fast, automatic, or unconscious" processes on the one hand and "slow, effortful, or conscious" processes on the other (see Evans 2008: 270; Kahneman 2011). One source of the affinity between Bourdieusian sociology and the contemporary cognitive sciences is that both are principled reactions to the faulty "Cartesian" conception of mind as perfectly rational and separable from the body (Bourdieu and Wacquant 1992: 5, 20, 26, 49; Willmott 1999; Uleman 2007). Both recognize the ubiquity and importance of unconscious, embodied cognition; in fact, Bourdieu's (e.g., 1977, 1990) notion of habitus is astonishingly compatible with emerging conceptions of the "cognitive unconscious" (Hassin et al. 2005; Lizardo 2009).

But unless we simply want to exchange the terms "habitus" for "cognitive unconscious" when we cross the interdisciplinary bridge, we need to work toward specifying more precisely the character of this compatibility. Like many of our colleagues (e.g., Lizardo 2004, 2009; Ignatow $2007,2009)$, we are quite optimistic about bringing together cognitive science and the Bourdieusian tradition and we hope our argument is interpreted with this in mind. Our concern is that the Bourdieusian distaste for "dualisms" risks rendering this cross-pollination less fruitful than it might otherwise be. We argue that there are two basic responses to faulty mind-body 
dualism. The first option, taken by the Bourdieusian tradition, is simply to reject it. The second option is to preserve what is of value in this classical dualism by better specifying it. Our thesis here is that respecification is preferable to rejection on both theoretical and empirical grounds. We will attempt to argue for this claim while demonstrating that it is compatible with the aims and commitments of Bourdieusian sociology.

We proceed as follows: first, we outline rejection and respecification as possible reactions to mind-body dualism and argue that the latter is a preferable option. Second, we use excerpts from Loïc Wacquant's seminal book, Body and Soul: Notebooks of an Apprentice Boxer, to demonstrate the usefulness of our analytic reformulation. We rely on this book because it is one of the most clearly articulated cases for mind-body holism in cultural sociology and because it contains both theoretical explanation and a deep engagement with empirical data. This will allow us to engage with both the theoretical logic and its application to a concrete case.

We hope to show that distinguishing between "practical" and "discursive" cognition (or, more accurately, between type 1 and type 2 cognitions [Evans 2008: 270-1]) and considering their interplay over time can shed additional light the social processes Wacquant identifies. We conclude by considering how a properly (that is, analytically) dualistic psychology might be grafted into a Bourdieusian sociology in ways that will benefit both research traditions.

\section{DEALING WITH DESCARTES: TWO RESPONSES TO THE FLAWS OF MIND-BODY DUALISM}

A strong distinction between body and mind is a dominant and recurring feature of the Western philosophical tradition. Mind-body dualism is most often associated with René Descartes, who claimed that mind "was a substance whose whole essence or nature is simply to think, and which does not require any place, or depend on any material thing, in order to exist" (Descartes, quoted in Hatfield 2008). This is not to say that Descartes rejected the importance of the body or did not consider some of what we today might call "automatic cognitions." For example, he argued that

[A] very large number of the motions occurring inside us do not depend in any way on the mind... When people take a fall, and stick out their hands so as to protect their head, it is not reason that instructs them to do this; it is simply that the sight of the impending fall reaches the brain and sends the animal spirits into the nerves in the manner necessary to produce this movement even without any mental volition, just as it would be produced in a machine (quoted in Hatfield 2008).

Despite such acknowledgements, Descartes saw the mind-body divide as fundamental. There is no need here to expound here on the limitations of this view; in this context it is enough to say that a great deal of research has shown that even the highest-order mental processes are dependent in crucial ways on the "embodied mind" (see e.g., Lakoff and Johnson 1999; Ignatow 2007, 2010). 
Although the embodied nature of mind is now rarely-if ever-explicitly denied, a great deal of research in sociology proceeds as if Descartes' dualism were correct (see related discussions in, e.g., Wrong 1961; Shilling 1997; Wilmott 1999; Ignatow 2007). But as scholars living at a time in which the embodiment of mind is firmly established, our question must not be whether to reject Descartes' strict mind-body dualism but rather what to put in its place. There appear to be two basic answers. The first is to reject Descartes' dualism as a false dichotomy. This is the path Bourdieu and Wacquant take, although we will argue in the conclusion that categorical rejection is not a necessary part of Bourdieusian theory. The second is to recognize that while body and mind are physically inseparable, we can nevertheless treat "mind" (Descartes' higher level, "type 2" cognitions) and "body" (lower level, "type 1" cognitions) as analytically distinguishable.

\section{Dualism Denied}

As a matter of theoretical commitment, it is not difficult to establish that Bourdieu and Wacquant regard body-mind holism as a key principle (see also Ignatow 2010). In their collaborative book, Invitation to Reflexive Sociology, the first sentence of Wacquant's summary of the Bourdieusian approach avers that it is "based on a non-Cartesian social ontology that refuses to split subject and object, intention and cause, materiality and symbolic representation..." (Bourdieu and Wacquant 1992: 5, emphasis added). Bourdieu himself makes a similar claim, stating that his theory "reject[s] all the conceptual dualisms upon which nearly all post-Cartesian philosophies are based: subject and object, material and spiritual, individual and social, and so on" (Bourdieu and Wacquant 1992: 122). While more dualisms are involved here than mind-body, rejecting this particular dualism is clearly a key theoretical commitment.

A firm dedication to mind-body holism persists in Body and Soul (2004), Wacquant's account of his years spent becoming a boxer at a gym on the South Side of Chicago. Using boxing as a case because of what it "can teach us about the logic of any practice" (p. 16), Wacquant begins his account with the claim that becoming a boxer is a process of "appropriat[ing] ... a set of corporeal mechanisms and mental schemata so intimately imbricated that they erase the distinction between the physical and spiritual," a process so deeply embodied that it "erases the boundary between reason and passion [and] explodes the opposition between action and representation" (p. 17, emphasis added). Following Marcel Mauss, who is an early founder of the Bourdieu-Wacquant tradition (see Ignatow, this volume), Wacquant advances a "theor[y] of social action" that regards human conduct as "physio-psycho-sociological assemblages of series of acts ... more or less habitual or more or less ancient in the life of the individual..." (p. 17). Wacquant's rejection of mind-body dualism (which includes rejecting corollary oppositions like reason and passion, representation and action) could not be clearer, nor could it be given greater theoretical emphasis.

In the strict ontological sense, Wacquant is completely justified in his holistic position. All forms of thinking, judging, reasoning, perceiving, learning, and so on are equally "embodied" in the sense Descartes rejected because they all "depend on [the] material thing" called the body 
(including particularly, though not exclusively, the brain). Even the "highest" forms of reasoning-such as philosophizing-are dependent in crucial ways upon "lower" processes (Lakoff and Johnson 1999; Evans 2008: 271). We now know beyond a reasonable doubt that no rigid ontological separation of mind and body is, in fact, possible (see Ignatow 2007).

\section{Defending (Analytical) Dualism}

In an analytic sense, however, rejecting these distinctions seems to us to go too far. Though we must dismiss the idea that there is no such thing as pure, disembodied consciousness, it does not follow that we must reject the fact that some cognitions are more "mind-like" in the traditional sense-conscious, reasoned, propositional, or "platform independent" - while others are more "body-like" - unconscious, passionate, procedural, or "platform dependent" (see Clark 2008: 43; Evans 2008: 270; Kahneman 2011). Indeed, this is the whole thrust behind dual-processing models in cognitive science. Nor would we be justified in declaring this analytic distinction "merely" analytic; although there are not discrete neurological systems for different types of cognition, they do draw on different elements of the brain and body disproportionately (see Evans and Stanovich 2013 for a recent overview).

What are the advantages of keeping these systems analytically distinct in our research? The tension between holism and dualism here resembles similar tensions around other classic polarities in social theory, such as structure and agency, structure and culture, micro and macro, among others (Archer 1995; Martin 2003). Though the potential pitfalls of generic holism have been discussed at greater length elsewhere (see e.g., Archer 1995), we discuss only two here that seem particularly salient to the "mind-body" issue.

First, Mauss, Bourdieu, and Wacquant are completely correct in their assertions that action is the result of "physio-psycho-sociological" processes and that strategies of action are "more or less habitual" (Wacquant 2004: 17). While we agree completely, we would like to put the emphasis on the disjunctive "or" in "more or less." That is, a particular form of knowledge or action associated with a particular social actor (or set of social actors) may properly be considered more habitual and "embodied" or less habitual and "embodied," depending on the phenomenon in question. Though a holistic approach tends to downplay these differences (precisely because it decides not to see them), we argue that it is worth paying attention to them because they can lead to additional insight into social processes.

Second, a holism that is "at once corporeal and mental" (Wacquant 2004: 16) does not provide theoretical leverage on examining how the "corporeal" and the "mental" can influence each other sequentially over time via analytically distinct types of processes. If-as asserted by holism-all learning is always simultaneously corporeal and mental, then we cannot ask whether and when the (more) "mental" becomes (more) "corporeal" and vice versa. 


\section{An Analytic Typology of Cognitive Socialization}

By combining an analytical dualism that distinguishes between "practical" (i.e., embodied, unconscious, type 1) and "discursive" (i.e., propositional, conscious, type 2) forms of cognition (Vaisey 2009) with a consideration of temporality, we can form a typology that may shed light on different dynamics of "cognitive socialization" in naturalistic settings (Zerubavel 1997; Lizardo 2009). Our simplified typology distinguishes between (1) social knowledge that starts and continues as practical knowledge; (2) social knowledge that begins discursively and gradually becomes practical; (3) social knowledge that is formed as practical knowledge but that its holders attempt to articulate discursively; and (4) social knowledge that remains primarily at the level of discursive consciousness. These processes, represented in Figure 1, are analytically distinct (like Weber's [1978] types of action) and are characterized by different causal dynamics, as we show below.

\section{[FIGURE 1 ABOUT HERE]}

\section{THE DIVIDENDS OF DUALISM: A BRIEF LOOK AT BODY AND SOUL}

To illustrate the value of this typology for analyzing the logic of social practices, we analyze a variety of episodes from Wacquant's Body and Soul. Revisiting the text with these four "idealtypical" modes of action in mind demonstrates how an analytically dualist approach to cognition can reveal subtle distinctions that are hard to detect using a holist approach.

\section{Staying in the Practical Realm: The Comprehension of the Body}

The first mode of action occurs when actors remain at the level of practical cognition throughout the acquisition of a practice. Three types of cognitive socialization described in Body and Soul in which actors seem to remain at the practical, automatic level of cognition are the cultivation of skills through repetitive drills and exercise routines, mimetic copying of the movements of others, and reflexive responses during sparring.

Floorwork, or the sequence of drills that are repeated by all boxers in the gym, "day after day, week after week, with only barely perceptible variations" (2004, p. 60), constitutes the core of the training regimen for boxers. Through seemingly endless cycles of shadowboxing, simulated boxing, bag punching, rope jumping, and strength training, boxers cultivate a "comprehension of the body" wrought through the repeated gestures and postures, which remains independent of conscious awareness. Wacquant writes:

There is a comprehension of the body that goes beyond-and comes prior to-full visual and mental cognizance. Only the permanent carnal experimentation that is training, as a coherent complexus of 'incorporating practices,' can enable one to acquire this practical mastery of the practical rules of pugilism, which precisely satisfies the condition of 
dispensing with the need to constitute them as such in consciousness" (2004 p. 69, emphasis added).

Here all learning is rooted in the comprehension of the body: bodily movements evolve into symbolic schemas and abstract concepts, as a child develops "higher order" knowledge from a set of "lower order" sensorimotor schemas (Piaget 2001, 1999, see also Lizardo 2009). Gallagher (1998) refines Piaget's concept of the body schema, which he describes as "the body's nonconscious appropriation of habitual postures and movements, its incorporation of various significant parts of the environment into its own experiential organization" (p. 226, see also Gallagher 2005). Gallagher distinguishes body schemas, which are "preintentional" and "never fully represented in consciousness" from body image, in which the body constitutes the "object or content of intentional consciousness" (1998, p. 226). Despite being nonconscious, body schemas are not passive or reflexive: the body "actively organizes" stimuli according to the circumstances and intentions of the individual (1998, p. 235).

Beyond the mere repetition of sequences of movements at the individual level, boxing gyms also cultivate practical knowledge through mimesis: a fighter is constantly surrounded by other bodies in motion, who act as visual models of the proper execution of each gesture. As Wacquant describes:

This continuous visual and auditory reinforcement generates a state of 'collective effervescence'... which has the effect of facilitating the assimilation of gestures by prodding participants to drop their inhibitions, to 'let go' of their bodies, to whip up their energy $(2004$, p. 116).

We can see that the synchronicity of the training routines often enables fighters to remain at the level of automatic cognition, without the interference of deliberate, conscious thought. Bourdieu (2001) speaks of a "practical mimesis" that is "opposed to both memory and knowledge and tend[s] to take place below the level of consciousness [and] has nothing in common with an imitation that would presuppose a conscious effort to reproduce a gesture, an utterance, or an object" (p. 73). As Lizardo astutely points out, mirror neurons are a possible mechanism allowing somatic knowledge to "'jump' from person to person" mimetically (2009, p. 717). They appear to light up when an animal sees, hears, and executes an action (2009). Just as Bourdieu and Wacquant have argued, witnessing others complete a sequence of action allows an individual to develop familiarity with that sequence of movements in much the same way as if she were executing the actions herself.

The third example of action that remains at the practical level in Body and Soul is the cultivation of reflexes during sparring. As Wacquant describes, sparring alters perception, as the boxer learns to filter out distractions and focus on the movements of his opponent (87), and instills in the fighter a "cultivated instinct," where the body of "computes and judges for him, instantaneously, without the mediation-and the costly delay that it would cause-of abstract thinking, prior representation, and strategic calculation" (97). This is an exceptionally clear example of Bourdieu's "practical sense," which is "instilled by the childhood learning that treats the body as a living memory pad, an automaton that 'leads the mind unconsciously along with 
it'"' (1990, p. 68). With the body operating as an automaton, skills and capabilities apprehended practically shape future behaviors much as instincts do, through mechanisms that remain imperceptible and inoperable to the conscious mind. Bourdieu writes, "What is "learned by body' is not something that one has, like knowledge that can be brandished, but something that one is" (1990, p. 73).

\section{From Discourse to Practice: Verbal Instructions and Regulation of Sparring}

All bodily knowledge, however, is not produced through practice alone. In several instances, the Woodlawn boxers move from the discursive realm to the practical realm, primarily when attempting to master a specific posture or movement. In his fieldnotes, Wacquant acknowledges the difference between this mode of transmission and the "carnal experimentation" described above. For example, in the short passage recounting how both coach DeeDee and fellow boxer Anthony attempt to instruct him on how to block an opponent's jab, there are at least six instances of verbal instructions given to Wacquant. Wacquant writes how "It's embarrassing to have this movement, seemingly so simple, explained to me again... I think I'm starting to grasp the mechanics better, but it's hard to go from mental comprehension to physical realization" (123, emphasis added). The text here suggests that Wacquant the ethnographer recognizes the separation between mental and practical understanding that he is committed to denying in a more theoretical mode.

Elsewhere in the narrative, DeeDee is trying to help Wacquant with his left hook. After repeated verbal descriptions of how the move should be executed, DeeDee runs out of patience and "grudgingly resigns himself to calling on the reflex of self-defense," announcing that he will tell Wacquant's sparring partner to teach him "with his left hook, if you don't wanna listen." Wacquant responds: "That's the best way to learn, right?" DeeDee reples: "No, it ain't the best way, it's the hard way. I rather you learn it on your own when I tell you, not by getting your face beat up" (103, emphasis in original). In this passage, both Wacquant and DeeDee are explicitly comparing the deliberate mode of verbal instruction with the "reflexive," automatic mode of bodily experience.

Likewise, another episode shows Wacquant's sparring partner freezing the action in order to verbally communicate instructions on the technique of a move. As he describes in his fieldnotes:

I move on Ashante right away and badger him with quick jabs, which he parries. He stops me in my tracks to tell me, "If you're coming at me, keep yo' han's up or I'monna deck you." Thanks for the advice, which I take into account by swiftly raising my guard. I resume my march forward (88, emphasis added).

The fact that Ashante chose to intervene in the middle of a match to relate this piece of advice demonstrates once again that boxers recognize the distinction between practical and discursive transmission of knowledge about boxing techniques. It seems from these examples that they deliberately choose between these two modes depending on the level of specificity of the 
information being expressed, in terms of the movements of the body. When the fighter needs advice about a particular move or an isolated part of the body, the discursive mode is preferred, while the practical mode is better for transmitting a "feel for the game" and for cultivating fluency in the sequences of moves required for success in the ring.

In addition to providing instructions for how to execute the techniques of boxing, the discursive mode often precedes the automatic mode in order to ensure the fighters' safety. This is particularly true during sparring matches, where boxer and coach must negotiate with each other to ensure that the sparring matches produce the optimal amount of exposure to combat while minimizing the risk of serious injury.

In the same passage describing the sparring match between Wacquant and Ashante, Wacquant describes the fighters' exchange during the break in between the second and third round: "[Ashante said] 'Tha's good Louie, you're doing good, you're punching har' today, keep it up.' [Wacquant replied] 'Yeah, the only problem is I'm not sure I can hold out for another round at this pace'" (90). Here, Wacquant is warning Ashante that his strength is waning, that he will be more vulnerable in the next round, so Ashante should lighten up or he may get hurt. And sure enough, when the fighting commences, Ashante lets up considerably and "pretends to be boxing but is only hitting me superficially" (90).

This discursive underpinning of sparring matches is also carried out on the sidelines, where the coach must monitor each fighter's progress to ensure that the delicate balance between exposure and risk is maintained. If a fighter oversteps the boundaries of the sparring match, the coach must intervene and verbally reprimand him. Wacquant gives an example, again discussing his experiences sparring with Ashante:

On 29 June 1989, I am dumbfounded to learn that Ashante complained to DeeDee that I hit too hard and that he is forced to respond by firing back solid shots right in the mug. "He told me he can't hav fun witchu no more, you hit too hard. You've made enough progress now, he gotta be careful to not let you land your punches or you can hurt him" (84-85).

As part of the practice of boxing, deliberate, intentional actions are sometimes required in order to ensure the safety of the practical, bodily actions in the ring.

The experiences Wacquant reports are in perfect agreement with the latest cognitive research on learning, which has learned that knowledge and goals "acquired reflectively through System 2 can, through repeated activation, be installed into rigid implicit processing mechanisms-a kind of automation of thought" (Evans 2008: 261). In other words, not everything has to be learned "the hard way."

\section{Practical to Discursive: "Corrective Face-work"}

The fighters portrayed in Body and Soul sometimes try to "make sense" verbally of rules and codes that are unspoken. In these instances, the boxers are moving from the practical mode of 
cognition, in which their judgments and decisions are automatic and subconscious, to the discursive, in which they, mindfully and intentionally, attempt to construct "post hoc" explanations of their actions and judgments (compare Haidt 2001; Wilson 2002). In the following passage, Wacquant describes how boxers resort to an "official explanation" to justify the unquestioned practical knowledge that only DeeDee should sit in a certain chair:

The high swivel armchair... is strictly reserved for the master of the premises. The official explanation is that DeeDee does not want anyone else to sit in it on grounds that they would stain it with their sweat. But the prohibition applies also to those who come dressed in civilian clothes and do not train... The hygienic excuse cannot hide the social reason behind this taboo: the armchair materializes DeeDee's place and function in the gym (2004 p. 40, emphasis added).

In this passage, Wacquant compares the "social reason," which is tacitly accepted by all but explicitly mentioned by none, to the "official explanation" that boxers offer when questioned. This official explanation does not adequately explain the full extent of the taboo on the chair, yet it survives in the discourse of the gym. The fighters "just know" that they shouldn't sit in the chair, but when asked to explain it, they attempt to construct a rational explanation for their moral judgments, an explanation which, constructed after the fact, turns out to be patchy and easily refuted by observing the practice itself (see Haidt 2001; Cushman, Young, and Hauser 2006; Vaisey 2009).

In another example of "post hoc" justification, Wacquant describes how, when a boxer flounders in a fight and threatens the hierarchy of the gym, other fighters quickly come to his aid and offer excuses to justify his actions:

Every time a boxer steps into the ring... he puts a fraction of his symbolic capital at stake: the slightest failing or slip-up... brings immediate embarrassment to the fighter, as well as to his gym-mates who hasten to assist his "corrective face-work" so as to restabilize the fuzzy and labile status order of the gym. Boxers have at their disposal a variety of socially validated excuses for this purpose, ranging from minor health hassles... to imaginary injuries... to the alibi most readily called upon... a breach of the sacrosanct code of sexual abstinence (79).

The term "corrective facework" is reminiscent of the rationales offered by the adult respondents in Swidler (2003) to explain their romantic love. Swidler describes how these individuals were choosing the most situationally appropriate justifications from a repertoire of cultural tropes to "make sense" of their actions for themselves and others. Like the boxers in Body and Soul, who select from "a variety of socially validated excuses," Swidler's respondents also chose from a "medley" of rationales; she writes, "If what one wants to do is support and justify a given way of life, having a variety of rationales available should strengthen one's position. If one argument fails, there are plenty of others available" (2003 p. 30). 


\section{Exclusively Discursive Behavior: "Rules is Rules"}

While the Woodlawn boxers share an implicit, intuitive moral code, they also answer to a series of explicit, clearly defined rules, many of which have only a distant, hypothetical connection to the sport of boxing. Wacquant reports how Mickey Rosario, a trainer at another gym in New York, instructs a new recruit to his gym:

Ok, first thing you got to know is the rules. We don't allow no cursing here. We don't allow no fighting, except in the ring. I ain't here to waste your time and you ain't here to waste mine. I don't smoke and I don't drink and I don't chase womens.... Rules is rules, no argument. You understand? (2004 p. 57).

Though Wacquant states that "initiation into boxing is an initiation without explicit norms" (2004 p. 102, emphasis in original), the prohibitions listed in the above passage are earlier contrasted with a "series of lesser and often implicit rules" (2004 p. 55), clearly implying that at least some rules are explicit and deliberately communicated to the fighters as a vital part of their apprenticeship. One fighter describes his experience attempting to follow the rules of the gym, "You know, dedication, when you gotta really dig deep down inside of you and go for what you want-you gotta say like well no women this month, you know, an' no hamburgers" (2004 p. 67, emphasis in original). This fighter's language speaks of the conscious intentionality of his attempt to follow these rules: he talks to himself and tries to suppress his desire in order to display his dedication to the sport. (Presumably no amount of embodied expertise would make avoiding sex or hamburgers completely "natural.")

While some of these prohibitions could potentially be linked to the sport of boxing in terms of maintaining physical strength and mental focus during training periods, others are inarguably pedantic: coach DeeDee "will not allow the expression 'to fight' to be used in lieu of 'to box' (or 'to spar' for sparring sessions)" (2004 p. 55). With no practical significance, these rules are consciously learned, deliberately followed, and verbally communicated. Such strict regulations serve to separate the "island of order and virtue" that is the gym from the surrounding disorder of the ghetto. By splitting hairs, the men at the gym signify their membership in a community where the unbridled passions of the street have no place.

\section{CONCLUDING DISCUSSION}

We want to clarify our intentions behind choosing to explicate this typology using examples from Wacquant's Body and Soul. We realize that by doing so, we run the risk of being interpreted as trying to pick apart Wacquant's analysis and reveal holes or falsehoods. This is far from our real objective, which is to build on-not criticize-his superb analysis of life in the gym. Leaving aside Wacquant's explicit denials of the dualism between the "mental" and "corporeal," we see abundant evidence that he fruitfully-if implicitly-relied on some version of this analytic tension in his explanation of the process of becoming a boxer. In any case, we freely acknowledge our limited understanding of the sorts of scenes described in the book, 
since we relied solely on Wacquant as a source and "enter[ed] the pugilistic universe only through the mediation of the written word" (Wacquant 2004 p. 70).

Despite these potential pitfalls, we chose to sketch our typology using examples from Body and Soul because we hoped that this would demonstrate that refining and specifying the duality between type 1 and type 2 cognition is fundamentally compatible with a Bourdieusian approach to sociological research. ${ }^{2}$ We chose Wacquant's book because it seamlessly combines theoretical reasoning and empirical observation, enabling us to make our argument concrete. We understand and agree with Wacquant's desire to establish distance from the exaggerated ontological dualisms of the Western philosophical tradition, but we firmly believe that respecifying the "mind-body" dualism in this manner adds valuable tools to the Bourdieusian repertoire that can help us to learn even more about "the logic of any practice."

We saw that Wacquant's actors rely on two analytically distinct types of cognition when learning both the postures of boxing as well as the rules of the pugilistic universe. They use type 1 cognition, with their bodies acting as "automatons," to gain a "feel for the game," to understand the flow and rhythm of the ring. Yet when trying to develop competencies around more specific movements, they begin in the discursive realm, explicitly describing the sequence of movements and the placement of each part of the body before such gestures slowly become bodily knowledge, accessible through automatic processes directly. In terms of the code of rules and expectations, boxers also use two modes of cognition. There are some rules that remain unspoken, that just "make sense" intuitively as boxers become part of the gym community. In contrast, other rules seem to make little sense at all on a practical level; they are imparted through verbal admonishments and advice, and appear to convey and uphold the order of the gym amid the disorder of the street.

The goal of our argument has been to suggest that an important item on the agenda for the ongoing dialogue between cognitive scientists and microsociologists is how to how to replace Descartes' flawed mind-body dualism. Although we agree that strict mind-body dualism should be laid to rest, we believe that replacing this dichotomy with a holistic theory risks making it harder for researchers to see analytic distinctions that make a real difference. Thus, we have argued that sociologists should replace the old dualism with a new, improved one that incorporates cognitive science regarding differences between habitual, embodied cognition and intentional, discursive cognition. This will help microsociologists and cognitive scientists be in the best possible position to understand, enrich, and improve each other's work.

\footnotetext{
${ }^{2}$ See also Vaisey and Lizardo (2010) for an example of combining analytical dualism and Bourdieusian sociology in a study of social network formation.
} 


\section{REFERENCES}

Archer, Margaret S. 1995. Realist Social Theory: The Morphogenetic Approach. New York: Cambridge University Press.

Campbell, Colin. 1996. The Myth of Social Action. New York: Cambridge University Press.

Clark, Andy. 2008. "Embodiment and Explanation." Pp. 41-58 in Handbook of Cognitive Science: An Embodied Approach, edited by Paco Calvo and Toni Gomila. San Diego, CA: Elsevier.

Cushman, Fiery, Liane Young, and Marc Hauser. 2006. "The Role of Conscious Reasoning and Intuition in Moral Judgment," Psychological Science 17 (12): 1082-1089.

DiMaggio, Paul. 1997. “Culture and Cognition.” Annual Review of Sociology 23:263-287.

Evans, Jonathan St B. T. 2008. "Dual-Processing Accounts of Reasoning, Judgment, and Social Cognition." Annual Review of Psychology 59:255-278.

Evans, Jonathan St B. T. and Keith E. Stanovich. (2013). "Dual-Process Theories of Higher Cognition: Advancing the Debate." Perspectives on Psychological Science 8(3), 223-241.

Gallagher, Shaun. 1998. "Body Schema and Intentionality," in The body and the self, José Bermudez, Anthony Marcel, and Naomi Elian, eds. MIT Press, 225-245.

Gallagher, Shaun. 2005. How the body shapes the mind. Oxford University Press.

Greene, Joshua, and Jonathan Haidt. 2002. "How (and Where) Does Moral Judgment Work?." Trends in Cognitive Sciences 6:517-523.

Greene, Joshua D., Leigh E. Nystrom, Andrew D. Engell, John M. Darley, and Jonathan D. Cohen. 2004. "The Neural Bases of Cognitive Conflict and Control in Moral Judgment." Neuron 44:389-400.

Haidt, Jonathan. 2001. "The Emotional Dog and Its Rational Tail: A Social Intuitionist Approach to Moral Judgment." Psychological Review 108:814-834.

Hassin, Ran, James S. Uleman, and John A. Bargh, eds. 2007. The New Unconscious. New York: Oxford University Press.

Hatfield, Gary. 2008. "René Descartes." in The Stanford Encylopedia of Philosophy, edited by Edward N. Zalta. http://plato.stanford.edu/entries/descartes/ (Accessed June 21, 2010).

Ignatow, Gabriel. 2007. "Theories of Embodied Knowledge: New Directions for Cultural and Cognitive Sociology?" Journal for the Theory of Social Behaviour 37:115-135.

Ignatow, Gabriel. 2009. "Why the Sociology of Morality Needs Bourdieu's Habitus." Sociological Inquiry 79:98-114. 
Ignatow, Gabriel. 2010. "Morality and Mind-Body Connections." Pp. 411-424 in Handbook for the Sociology of Morality, edited by Steven Hitlin and Stephen Vaisey. New York: Springer.

Kahneman, Daniel. 2011. Thinking Fast and Slow. Farrar, Straus and Giroux.

Lakoff, George, and Mark Johnson. 1999. Philosophy in the Flesh : The Embodied Mind and Its Challenge to Western Thought. New York: Basic Books.

Lizardo, Omar. 2009. "Is a "Special Psychology" of Practice Possible? From Values and Attitudes to Embodied Dispositions." Theory Psychology 19:713-727.

Lizardo, Omar. 2007. "Mirror Neurons, Collective Objects and the Problem of Transmission: Reconsidering Stephen Turner's Critique of Practice Theory." Journal for the Theory of Social Behaviour 37:319-350.

Lizardo, Omar. 2004. "The Cognitive Origins of Bourdieu's Habitus." Journal for the Theory of Social Behaviour 34:375-401.

Martin, John Levi. 2003. "What Is Field Theory?" American Journal of Sociology 109:1-49.

Shilling, Chris. 1997. "The Undersocialized Conception of the Embodied Agent in Modern Sociology." Sociology 31:737-764.

Smith, Christian. 2003. Moral, Believing Animals: Human Personhood and Culture. New York: Oxford University Press.

Stam, Henderikus J. 2009. "Habitus, Psychology, and Ethnography: Introduction to the Special Section." Theory Psychology 19:707-711.

Swidler, Ann. 2003. Talk of Love: How Culture Matters University of Chicago Press.

Uleman, James S. 2007. "Introduction: Becoming Aware of the New Unconscious." Pp. 3-15 in The New Unconscious, edited by Ran Hassin, James S. Uleman, and John A. Bargh. New York: Oxford University Press.

Vaisey, Stephen. 2009. "Motivation and Justification: A Dual-Process Model of Culture in Action." American Journal of Sociology 114:1675-1715.

Vaisey, Stephen and Omar Lizardo. 2010. “Can Cultural Worldviews Influence Network Composition?" Social Forces.

Willmott, Robert. 1999. "Structure, Agency and the Sociology of Education: Rescuing Analytical Dualism." British Journal of Sociology of Education 20:5-21.

Wilson, Timothy D. 2002. Strangers to Ourselves: Discovering the Adaptive Unconscious. Cambridge: Harvard University Press. 
Wrong, Dennis H. 1961. "The Oversocialized Conception of Man in Modern Sociology." American Sociological Review 26:183-193.

Zerubavel, Eviatar. 1997. Social Mindscapes: An Invitation to Cognitive Sociology. Cambridge, MA: Harvard University Press.

\section{FIGURE}

Figure 1. Four Analytic Types of Cognitive Socialization

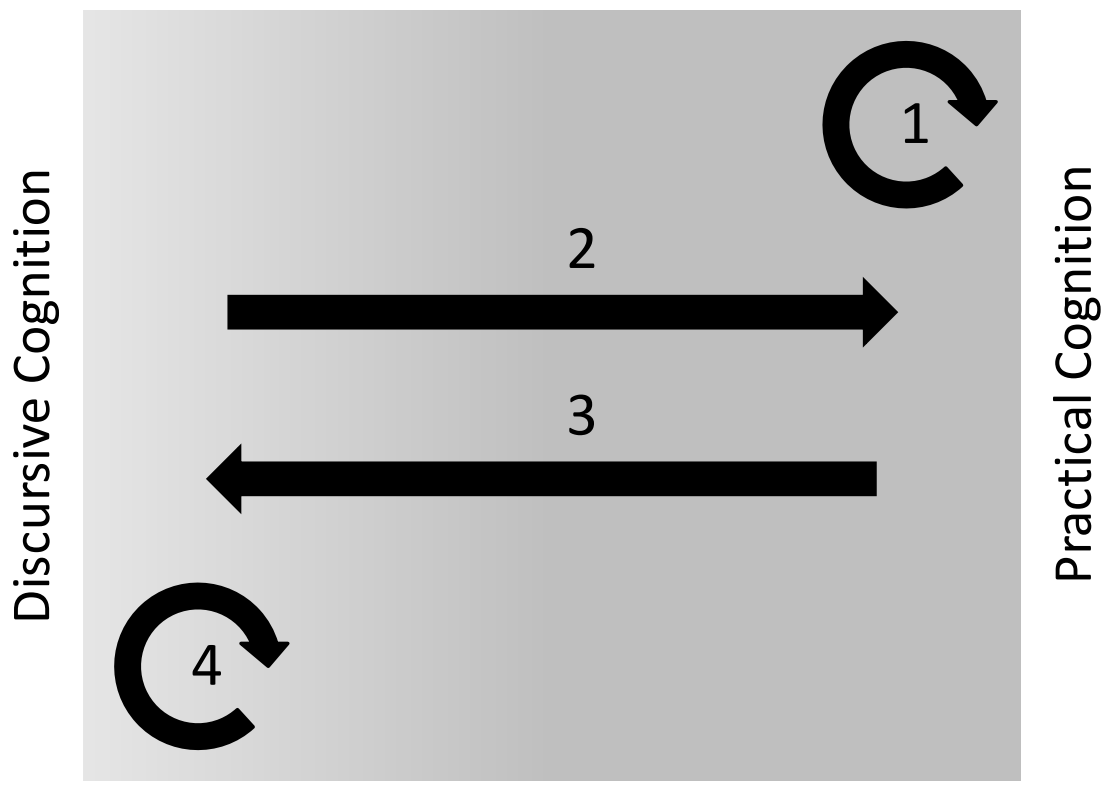

NOTE: the directions of the arrows represent the passage of time. The four types are: (1) social knowledge that starts and continues as practical knowledge; (2) social knowledge that begins discursively and gradually becomes practical; (3) social knowledge that is formed as practical knowledge but that its holders attempt to articulate discursively ; and (4) social knowledge that remains primarily at the level of discursive consciousness. 